\title{
OVARIAN FOLLICULAR CELLS - LIVING IN THE SHADOW OF STEMNESS CELLULAR COMPETENCE
}

\author{
Lisa Moncrieff ${ }^{1}$, Paul Mozdziak², Michal Jeseta ${ }^{3}$, Marie Machatkova $^{4}$, Wiesława Kranc ${ }^{5}$, Bartosz \\ Kempisty $3,5,6$
}

\begin{abstract}
Granulosa cells (GCs) are a major component found in ovarian follicular fluid among oocytes, theca cells, and ovarian surface epithelial (OSE) cells. GCs are steroidogenic and have morphological functions that are important for the development of the follicular follicle. The follicle protects the developing female egg. GCs are also essential for the maturation of the female germ cell. Stem cell properties have been found in luteinised GCs and in vivo cultures have the potential to differentiate to become cells found outside of the ovary. Both three-dimensional (3D) culturing and mouse embryonic fibroblast (MEF) medium have been used to help improve the culturing lifespan of GCs so that their profound proliferation and differentiation capabilities can be studied. Small RNAs called MicroRNAs (miRNAs) are released from exosomes originating from GCs, and they are involved in transforming growth factor (TGF)- $\beta$ signalling, follicle-stimulating hormone, hormone-related miRNAs, and apoptosis-related pathway. Finding the miRNAs involved in these pathways, and the mechanisms controlling GCs are important to treating conditions like polycystic ovary syndrome (PCOS), and creating new drug therapies. Besides GCs, ovarian stem cells (OSCs) were discovered in the OSE, and they are believed to be derived from very small embryonic stem cells (VSELs). Transplanting blood mononuclear cells, cell Hormone Therapy (cHT) with bone marrow stem cell supplement and increasing vitamin $\mathrm{C}$ levels are all therapies currently being researched into that involve GCs to combat the effects of aging and infertility.
\end{abstract}

Running title: Stemness of ovarian follicular cells

Keywords: microRNAs, ovarian stem cells, infertility treatments

\footnotetext{
${ }^{1}$ School of Medicine, Medical Sciences and Nutrition, University of Aberdeen, Aberdeen, United Kingdom

${ }^{2}$ Physiology Graduate Program, North Carolina State University, Raleigh, NC, USA

${ }^{3}$ Department of Obstetrics and Gynecology, University Hospital and Masaryk University, Brno, Czech Republic

${ }^{4}$ Veterinary Research Institute, Brno, Czech Republic

${ }^{5}$ Department of Anatomy, Poznan University of Medical Sciences, Poznan, Poland

${ }^{6}$ Department of Histology and Embryology, Poznan University of Medical Sciences, Poznań, Poland

* Correspondence: bkempisty@ump.edu.pl

Full list of author information is available at the end of article
} 


\section{Introduction}

Granulosa cells (GCs), otherwise known as ovarian follicular cells, are the largest component of follicular fluid [1]. Alongside GCs are theca cells, ovarian surface epithelial (OSE) cells, and oocytes. Together, the Graafian follicle will form to protect the oocyte (folliculogenesis) and germ cells also mature into an egg (oogenesis) [2,3]. Granulosa cells have small cell-secreted vesicles called exosomes which are essential in mediating communication between cells, and they share this role with gap junctions [4]. Exosomes secrete small-non coding RNAs, known as MicroRNA (miRNAs) [5]. These miRNAs have recently been found to be highly involved in the transforming growth factor (TGF)- $\beta$ signalling pathway. This pathway is necessary for folliculogenesis and oogenesis, and therefore manipulating exosomes secreted by granulosa cells may provide information on how both processes work. Additionally, since the work of Kossowska-Tomaszcuk and colleagues, diverse stem cells derived from GCs have been cultured that can differentiate into tissues not found in the ovaries and thus demonstrate their stemness [6]. Ovaries have heterogeneity stem cells, meaning they have a pluripotent stem cell population that is in a state of inactivity (quiescent) and mesenchymal cells that are active [7-9]. These two stem cell populations are found in the OSE [10]. The pluripotent stem cells are called very-small embryonic stem cells (VSELs) and are the progenitors of the mesenchymal stem cell population [11,12]. VSELs are thought to migrate to different organ tissues [13]. These pluripotent stem cells will self-renew until cells in damaged tissue need to be replaced [10]. The mesenchymal stem cell population in the OSE are called ovarian stem cells (OSCs). OSCs are larger in size and committed to differentiating into primordial follicles $[10,14]$. Research groups are going into individual avenues on how GCs, VSELs and OSCs could potentially be used in clinical applications. One of the main interests in using stem cells found in the ovaries is for restoring female fertility, but regeneration of tissues like the heart are also being researched and stem cells may also be used as a model for greater understanding of cell differentiation and epigenetics $[15,16]$.

It is important to understand cells in the follicular fluid, including the GCs, and their roles concerning their involvement in the development of the oocyte. Therefore, the characteristics of GCs, and methods of culturing them to differentiate into cardiac cells and other cell types are important considerations as well as the characteristics of the exosomes secreted by GCs. Furthermore, the mechanisms that protect the oocyte and other cells from oxidative stress are important considerations. The potential ovarian stem cell label, and the effects of oocyte aging are important issues worthy of further consideration.

\section{Characteristics of Granulosa Cells}

GCs have many functions in their lifetime such as ovarian follicular development; secretion of sex hormones and synthesising growth factors to induce oocyte growth [17]. Nutrients are also provided by GCs to developing oocytes via gap junctions [18]. The processes folliculogenesis and oogenesis occur in parallel so that the matured ovum will be protected by the matured Graafian follicle [2]. When the primordial follicles are made in fetal life, and composed of a stagnant oocyte layered by flat GCs, these processes begin [19]. For the Graafian follicle to form, a dominant follicle must be made from primordial follicular cells and then differentiate into the corpus luteum at ovulation [20,21]. Follicles are located inside the ovary cortex, below the OSE $[22,23]$. Gonadotropins and growth factors stimulate GCs to change their gene expression and morphology $[16,17]$, so flat-shaped GCs will become cuboidal, and express the Follicle Stimulating Hormone Receptor (FSHR) [2].

For large-scale production of progesterone, structural and functional changes also occur as GCs, stimulated by luteinising hormone (LH) or human chorionic gonadotropin ( $\mathrm{hCG}$ ), differentiate to be luteinising GCs [20]. However, it has been suggested that there are inhibitory factors for GC differentiation in follicular fluid, as neither LH or hCG is required for the cells to change their structure when removed from follicular fluid [20].

There are two specialised cell types of GCs, with distinct functions, called mural GCs and cumulus cells $[18,24-26]$. During folliculogenesis, from the transition of the preantral and antral follicle stage, mural GCs and cumulus cells are made from a common progenitor. One type is responsible for the production of oestrogen during the follicular phase, and progesterone after ovulation, the mural GCs. This is the cell type sheaths the theca cell layer. $\mathrm{Cu}$ mulus cells tightly surrounds the oocyte and make the cumulus oophorus and corona radiata inner cell layers. The innermost cell layer is the periantral layer, and the outermost layer is called the membrana granulosa [18]. These four layers have their own specialised functions. The GC cell types work together to fulfil oocyte growth, maintain oocyte quality and conduct steroidogenesis.

\section{Culturing Granulosa Cells}

GCs appear to have stem-like qualities given their adept proliferation in vitro [27]. Even though GCs do not do this in a follicular environment, GCs differentiate in long-term cultures [1,2]. To harness the full potential of GCs and their stem-like abilities, methods of extending its in vitro lifespan and controlling their gene expression must be revealed. Marker genes for the functions of cell differentiation, cell proliferation, and cell-cell junction organisation 
have also been found using RT-qPCR and these genes can be used to manipulate GCs to a higher degree [26]. GC differentiation can be induced using pluripotent stem cell markers $[6,15,27]$. The first to demonstrate that GCs have pluripotency and subsequently to differentiate the cells into lineages outside of the ovary was Kossowska-Tomaszczuk and his colleagues $[16,27]$. Luteinized GCs were collected from infertile women who were involved in a fertility program and treated with hormone therapies [6]. Elongated culture life-spans were accomplished by using leukaemia inhibitory factor (LIF) to maintain the cells in an undifferentiated state, and after long culture periods, the investigators demonstrated that luteinised GCs can become three germ cell types: neurons, chondrocytes, and osteoblasts once placed in the inductive cell type-specific environments. Bruckova improved the long-term lifespan of luteinised GCs by adding follicular fluid, and the cultures survived 45 days [28]. The DNA methylation inhibitor 5-azacytidine (5-aza-CR) and treatment of VEGF (vascular endothelial growth factor) was able to drive GCs to differentiate into muscle cells $[15,29]$. The investigators also found that the differentiation of the GCs was reversed when 5-aza-CR was removed, which assures the safety of the procedure. Furthermore, their results gave indication of epigenetics during cell conversion as chromatin decondensation occurred while the pluripotency markers were upregulated and led to loss of the GC morphology. It has also been observed that GCs can differentiate into chondrocytes [26]. Through increasing the period of luteinising GCs culture by using LIF, and using a matrix that included collagen type I, cultures retained the FSH receptor and formed into follicle-like structures [21]. Culturing GCs in a three-dimensional (3D) culture has been effective in increasing the life-span and quality of the cells in vitro and has benefitted scientists understanding of the cell type [30]. The expression of 39 genes related to heart development and morphogenesis were also found in GCs [16] suggesting that in long-term culture, GCs could differentiate into pre-cursors for cardiac cells [31]. A different study used mouse embryonic fibroblast (MEF) medium to grow human GCs with the aim to prolong GC in vivo life further and encourage proliferation by including growth factors, cytokines and facilitate cell-cell interaction, and more than 12 months later isolated the GCs [30]. Only 5\% of the granulosa passages became an immortalised cell line and stayed continuous after more than 100 passages. Follicle-like structures were formed from some of the other passages from the same GC population, after isolation of the GCs.

\section{Characteristics of Exosomes and Cell Stress}

Bi-direction growth of the embryo occurs due to the communication between the cells in the follicular fluid including GCs and oocytes [32]. Gap junctions or exosomes, secreted by GCs mediate this communication [4]. Other eukaryotic cells can secrete these membrane vesicles, and the quality of exosomes is dependent on the state of the releasing cell [33]. A recent study has suggested that other cells in follicular fluid-like oocytes or theca cells may secrete exosomal-like vesicles, but that the majority originated from mural GCs [34]. Furthermore, exosomes carry proteins and MicroRNAs (miRNAs) [5]. With the technique of small RNA sequencing, mural GCs and cumulus cells have been shown to secrete over 50 miRNAs differentially [25]. In folliculogenesis, oogenesis, tumorigenesis and tumour suppression, miRNAs are tightly involved in the transforming growth factor (TGF)- $\beta$ signalling pathway [35]. The expression profile of miRNAs was also studied in the cumulus GCs of patients suffering from polycystic ovary syndrome (PCOS) [36]. In nearly 60 miRNAs, the expression was different compared to those of the control. In addition, these differential miRNAs were targeting numerous pathways that could be associated with PCOS such as the Notch signalling pathway. GCs also seem to be regulated by miRNAs in pathways such as FSH, hormone-related miRNAs, and apoptosis-related pathways [37]. In studying miRNAs effects on these pathways, hundreds of genes could be regulated by one miRNA, and a single gene can be affected by more than one miRNA. miR320 could either stimulate GC steroidogenesis or suppress it [37]. Understanding the role of miRNAs in pathways, therefore, builds knowledge on the processes and creates the potential to modify them. To isolate exosomes, and also learn more about their optimal stability, one study claims exosomes prefer an acidic environment as more exosomal markers, proteins and RNA were found in a lower $\mathrm{pH}$ compared to the non-acidic environments [38].

Cell stress such as heat shock, hypoxia and disease can activate exosomes and cause GCs to secrete them [4]. The methods of uptake include endocytosis, simple fusion, exosomal surface ligands, and the modification outcome will be influenced by the exosome cargo molecule. Exosomes may be employed as a drug delivery vehicle, due to their small size and transport role [39]. One drug that can be carried by exosomes is curcumin [40] which has potential in treating numerous diseases, but it is not water soluble, or readily absorptive. However, curcumin's faults can be rectified by encapsulating the drug into a milk exosome to improve absorption [40]. GC dysfunction, exhibiting low hormone release and a reduction in cell proliferation, can be reversed through exosome delivered curcumin cells [39]. LPS was used to induce inflammation in GC cells, and various studies have confirmed its effectiveness in increasing pro-inflammatory cytokines and disrupting endocrine function. However, curcumin primed exosomes successfully caused GC cells to regain their normal function. 


\section{Ovarian Stem Cells and Very Small- Embryonic Like Stem Cells}

It was long thought that the number of eggs a mammalian female will make is capped in their pre-natal life and that humans are born with 500$1,000,000$ primordial follicles [41]. The supply of oocytes then dwindles in later life, leading to menopause, strongly affecting the hormones produced in the body and fertility. However, the existence of ovarian stem cells (OSCs) were identified by a lab led by Jonathan Tilly in 2004 during a mice study, in which the conserved germ cell marker DEAD box polypeptide 4 (Ddx4) was found in mitotically-active cells of juvenile and adult mice [42]. Mathematically, the possibility of ovarian stem cells that differentiated into oogonia seemed necessary as the number of cells that a female is born with would run out prematurely before normal menstrual age. Hence, new cells must be produced in post-natal life [42].

Since the discovery of OSCs, there has been scepticism surrounding their adult stem cell label and also criticism of the techniques of identifying them. Antibody-based magnetic-assisted cell sorting (MACS) and then antibody-based fluorescence-activated cell sorting (FACS) using Ddx4 to further study OSCs, was criticised. Ddx4 is a cytoplasmic protein found in oocytes, sperm, and primordial germ cells, and therefore it would not be an appropriate technique to isolate OSCs. On the other hand, it has been later verified that Ddx4 has a different localisation in OSCs, which has it on the cell surface [43]. This still runs the risk of contamination of other cell types, so FACS is a necessary step for purification. Furthermore, OSCs can be very gently scraped from OSE, so Ddx4 remains only a methodical issue rather than evidence used against OSCs existence [10].

Alongside OSCs are the smaller stem cell population in the ovaries, very small pluripotent stem cells (VSELS). The former expresses OCT-4A, whilst the latter expresses OCT-4B [10]. This change in OCT-4 is due to asymmetric cell division of VSELs, which cause the re-localisation of OCT-4 from the nuclear membrane to the cytoplasm in mesenchymal stem cells [13]. Both populations respond to FSH, the hormone released for folliculogenesis. If the expression of OCT4 is increased, this increases the likelihood of OSCs differentiating into oocyte-like cells [44]. It took so long to discover VSELs partly due to the fact that centrifugation did not include the small cells in the pellets [45]. A future application to isolate VSELS could be using high-speed centrifugation [7].

\section{The Effects of Aging on Follicular Fluid Cells and Fertility Treatments}

Understanding follicular fluid cells such as GCs, has allowed the effects of aging on oocyte quality and overall fertility to be shown, which has prompted studies to overcome the natural loss of fertility, as well as restore fertility for patients with prema- ture ovarian failure (POF) $[12,17,27,44,46-48]$. POF is a condition that describes the loss of function of female fertility before the age of 40 . It can occur due to various reasons such as chemotherapy or genetics. The ovaries of these patients function abnormally and lower levels of sex hormones like oestrogen are synthesised. As a consequence, ovulation occurs infrequently. To restore fertility, VSELS still have potential to be used after cancer treatment as they are not eliminated by chemotherapy $[7,49]$. They survive toxic insults due to their quiescent ability, however, this characteristic has the downside of making them not divide readily in culture [13].

Stem cells can be directed to the germ cell lineage [42,50,51]. Specifically, flow cytometry employing on germline-specific fluorescent gene markers, isolated VSELS. Inhibitory factors (and therefore their quiescent state characteristic) were overcome in vivo and resulted in spontaneous differentiation of VSELs to oocyte-like structures and male germ cells [51]. This highlights future applications, especially towards replacing eggs derived from aged primordial follicles that have lost quality and are less likely to be fertilised. Another lab studied the effects of aging on stem cells and concluded that older mice had fewer stem cells found in the OSE and that their gene markers for differentiation was different compared to those collected from young mice [52]. A different study looked into the effects of aging in humans [27]. They grouped women up according to their ages and found that follicular mesenchymal stem markers are expressed differently depending on the age of the women, most strikingly when the youngest group was compared to the oldest group. The youngest had cells with a higher expression of genes related to osteogenic and adipogenic differentiation, with the highest expression of FGF2 compared to the three other age groups. The oldest group's stem cells had the least potential of differentiating into osteogenic and adipogenic lineages in vitro, as FGF2 was the most downregulated out of all the control groups and it was the only group that expressed WNT3A. Furthermore, POU5F1 (OCT-4) was only shown to be expressed in the oldest and youngest groups, but not the two middle groups. Thus, gene expression is influenced by the cell environment.

OSCs obtained from older women require GCs for IVF or IVM to be successful [53]. Another study concluded that oocytes grow more in GC-rich follicular fluid, compared to oocytes grown in a GC-poor one [54]. GCs are essential for folliculogenesis and oogenesis, as well as regulating hormone levels, to ensure the maturation of oocytes. Additionally, menopausal age seems to correlate with the supply of GCs decreasing, due to inactivity of OSE differentiating and homeostatic immunological changes [7].

The environment surrounding the cells can induce normal ovarian activity and it can benefit from transplantation of younger cells $[12,55]$. For ex- 
ample, it has been suggested that the potential of older patients OSCs can be improved to differentiate into both developing oocytes and GCs through transplanting blood mononuclear cells from young, fertile patients [53]. Another treatment method is cell Hormone Therapy (cHT) [12]. The cHT method uses granulosa and theca cells to help create a young, ovarian environment, by trying to replicate ovarian follicles and encourage OSCs to move from an inactive state to developing into a mature egg. It was also discovered that cHT does not synthesise the same levels of hormones as normal specimens. To compensate for the inefficient hormone production, bone marrow-derived mesenchymal stem cells were added as oestrogen production may be encouraged by them resultingin a slight increase of viable cells. In addition, the negative feedback of oestrogen decreased the release of FSH and LH. This type of cHT increased the in vivo cell lifetime to the end of the experiment (at least three weeks more than without the bone marrow stem cell supplement) in rats, which is the equivalent of increasing their productive lifetime to $1 \%$. Additionally, it has been demonstrated that increasing doses of vitamin $C$ could act to combat ovarian aging [55]. Furthermore, the volume of the ovaries increased and there was also a rise in GC numbers [54].

\section{Conclusions}

GCs are a central component of follicular fluid and interact with various cells to ensure the development of the oocyte. Folliculogenesis and oogenesis require the participation of GCs for their hormone secretions and morphological structure. Few studies have examined the characteristics of GCs, as experts have possibly moved their focus on to the more complex interactions of GCs with other cells. Since the discovery that GCs can differentiate further into other cell types, there has been research into stem cell markers and attempts at improving culture. Attempts to improve the culture through 3D methods or MEF medium have been attempted. Further improvements on extending their culture lifespan must be made to examine the GCs differentiation. Interest has also been building on miRNAs secreted from exosomes and their effects on pathways involving GCs. Using the miRNAs identified in the processes of oogenesis and others, more research on them should be found to understand PCOS and other conditions. In addition, curcumin primed exosomes have been shown to successfully treat GC dysfunction and has great potential as a drug delivery vehicle. Despite GCs stem cell potency, more interest seems to have been given to OSCs and VSELS. The germ-line theory of mammalian females being limited supply to the number primordial follicles they were born with had been put into question at the discovery of OSCs. To ensure the validation of OSCs, various labs have used techniques like MACS, antibody based FACS and even simple scraping the cell from OSE to isolate the cells and study them. OSCs are also believed to be derived from VSELS. OSCs and VSELS are mostly being studied for reproductive clinical uses, but GCs may benefit other tissues found outside the reproductive system. The follicular fluid cells decrease in number and lose quality due to aging. Altering the stem cell environment affects their differentiation, with younger cells having the most potential. Experimental treatment models have been researched to treat fertility problems, such as blood mononuclear cell transplantations, cHT supplemented with bone marrow stem cells and increasing doses of vitamin C. For all these treatments, GCs are involved as they are essential for normal reproductive function. Through these treatments, the decline in quality and number of oocytes caused by menopause and POF can be overcome, highlighting the importance of these clinical methods.

\section{Ethical approval}

The conducted research is not related to either human or animal use.

\section{Corresponding author}

Bartosz Kempisty, Department of Anatomy, Poznan University of Medical Sciences, 6 Święcickiego St., 60-781 Poznań, Poland, Tel./Fax: +48 61 8546567, e-mail: bkempisty@ump.edu.pl.

\section{Conflict of interest statement}

The authors declare they have no conflict of interest.

\section{References}

1. Lai D, Xu M, Zhang Q, Chen Y, Li T, Wang Q, Gao Y, Wei C. Identification and characterization of epithelial cells derived from human ovarian follicular fluid. Stem Cell Res Ther. 2015;6; DOI:10.1186/s13287-015-0004-6.

2. Kranc W, Chachuła A, Bryja A, Ciesiółka S, Budna J, Wojtanowicz-Markiewicz K, Sumelka E, Borys S, Antosik P, Bukowska D, Bruska M, Nowicki M, Kempisty B. Selected molecular and physiological aspects of mammalian ovarian granulosa cells in primary culture. Med Weter 2016;72:723-7; DOI:10.21521/mw.5606.

3. Kottarathil VD, Antony MA, Nair IR, Pavithran K. Recent Advances in Granulosa Cell Tumor Ovary: A Review. Indian J Surg Oncol. 2013;4:3747; DOI:10.1007/s13193-012-0201-z.

4. Saeed-Zidane M, Linden L, Salilew-Wondim D, Held E, Neuhoff C, Tholen E, Hoelker M, Schellander K, Tesfaye D. Cellular and exosome mediated molecular defense mechanism in bovine granulosa cells exposed to oxidative stress. PLoS One. 2017;12; DOI:10.1371/journal.pone.0187569.

5. Da Silveira JC, Winger QA, Bouma GJ, Carnevale EM. Effects of age on follicular fluid exosomal microRNAs and granulosa cell transforming gro$w$ th factor- $\beta$ signalling during follicle development in the mare. Reprod Fertil Dev. 2015;27:897-905; DOI:10.1071/RD14452.

6. Kossowska-Tomaszczuk K, De Geyter C, De Geyter M, Martin I, Holzgreve W, Scherberich A, Zhang H. The Multipotency of Luteinizing Granulosa Cells Collected from Mature Ovarian Follicles. Stem Cells. 2009;27:2109; DOI:10.1634/stemcells.2008-0233.

7. Bhartiya D, Patel H, Sharma D. Heterogeneity of Stem Cells in the Ovary.Adv Exp Med Biol. 2019;1169:213-23; DOI:10.1007/978-3-030-24108-7_11.

8. Tang DG. Understanding cancer stem cell heterogeneity and plasticity. Cell Res. 2012;22:457-72; DOI:10.1038/cr.2012.13.

9. Li N, Clevers H. Coexistence of quiescent and active adult stem cells in mammals. Science (80- ). 2010;327:542-5; DOI:10.1126/ science.1180794.

10. Bhartiya D, Patel H. Ovarian stem cells-resolving controversies. J Assist Reprod Genet. 2018;35:393-8; DOI:10.1007/s10815-017-1080-6.

11. Lahlil R, Scrofani M, Barbet R, Tancredi C, Aries A, Hénon P. VSELs Maintain their Pluripotency and Competence to Differentiate after Enhanced Ex Vivo Expansion. Stem Cell Rev Reports. 2018;14:510-24; DOI:10.1007/s12015-018-9821-1. 
12. Sittadjody S, Enck KM, Wells A, Yoo JJ, Atala A, Saul JM, Opara EC. Encapsulation of Mesenchymal Stem Cells in 3D Ovarian Cell Constructs Promotes Stable and Long-Term Hormone Secretion with Improved Physiological Outcomes in a Syngeneic Rat Model. Ann Biomed Eng. 2019; DOI:10.1007/s10439-019-02334-w.

13. Bhartiya D, Shaikh A, Anand S, Patel H, Kapoor S, Sriraman K, Parte S Unni S. Endogenous, very small embryonic-like stem cells: critical review, therapeutic potential and a look ahead. Hum Reprod Update. 2016;23:41-76; DOI:10.1093/humupd/dmw030.

14. Parte S, Patel H, Sriraman K, Bhartiya D. Isolation and characterization of stem cells in the adult mammalian ovary. Methods Mol Biol. 2015;1235:203-29; DOI:10.1007/978-1-4939-1785-3_16.

15. Brevini TAL, Pennarossa G, Rahman MM, Paffoni A, Antonini S, Ragni G, deEguileor M, Tettamanti G, Gandolfi F. Morphological and Molecular Changes of Human Granulosa Cells Exposed to 5-Azacytidine and Addressed Toward Muscular Differentiation. Stem Cell Rev Reports. 2014;10:633-42; DOI:10.1007/s12015-014-9521-4.

16. Kranc W, Brązert M, Celichowski P, Bryja A, Nawrocki MJ, Ożegowska K, Jankowski M, Jeseta M, Pawelczyk L, Bręborowicz A, Rachoń D, Skowroński MT, Bruska M, Zabel M, Nowicki M, Kempisty B. "Heart development and morphogenesis" is a novel pathway for human ovarian granulosa cell differentiation during long-term in vitro cultivation-a microarray approach. Mol Med Rep. 2019;19:1705-15; DOI:10.3892/ mmr.2019.9837.

17. Vermeulen M, Giudice M-G, Del Vento F, Wyns C. Role of stem cells in fertility preservation: current insights. Stem Cells Cloning. 2019;12:27-48; DOI:10.2147/SCCAA.S178490.

18. Dzafic E, Stimpfel M, Virant-Klun I. Plasticity of granulosa cells: on the crossroad of stemness and transdifferentiation potential. J Assist Reprod Genet. 2013;30:1255-61; DOI:10.1007/s10815-013-0068-0.

19. Kranc W, Brązert M, Budna J, Celichowski P, Bryja A, Nawrocki MJ, Ożegowska K, Jankowski M, Chermuła B, Dyszkiewicz-Konwińska M, Jeseta M, Pawelczyk L, Bręborowicz A, Rachoń D, Bruska M, Nowicki M, Zabel M, Kempisty B. Genes responsible for proliferation, differentiation, and junction adhesion are significantly up-regulated in human ovarian granulosa cells during a long-term primary in vitro culture. Histochem Cell Biol. 2019;151:125-43; DOI:10.1007/s00418-018-1750-1.

20. Myers M, van den Driesche S, McNeilly AS, Duncan WC. Activin A reduces luteinisation of human luteinised granulosa cells and has opposing effects to human chorionic gonadotropin in vitro. J Endocrinol. 2008;199:201-12; DOI:10.1677/JOE-08-0302.

21. Kossowska-Tomaszczuk K, De Geyter C. Cells with stem cell characteristics in somatic compartments of the ovary. Biomed Res Int 2013;2013:310859; DOI:10.1155/2013/310859.

22. Nakayama M, Manabe N, Nishihara S, Miyamoto H. Species-specific Differences in Apoptotic Cell Localization in Granulosa and Theca Interna Cells during Follicular Atresia in Porcine and Bovine Ovaries. J Reprod Dev. 2000;46:147-56; DOI:10.1262/jrd.46.147.

23. Bukovsky A, Svetlikova M, Caudle MR. Oogenesis in cultures derived from adult human ovaries. Reprod Biol Endocrinol. 2005;3; DOI:10.1186/1477-7827-3-17.

24. Varras M, Griva T, Kalles V, Akrivis C, Paparisteidis N. Markers of stem cells in human ovarian granulosa cells: Is there a clinical significance in ART? J Ovarian Res. 2012;5; DOI:10.1186/1757-2215-5-36.

25. Andrei D, Nagy RA, van Montfoort A, Tietge U, Terpstra M, Kok K, van den Berg A, Hoek A, Kluiver J, Donker R. Differential miRNA Expression Profiles in Cumulus and Mural Granulosa Cells from Human Pre-ovulatory Follicles. MicroRNA. 2018;8:61-7; DOI:10.2174/22115366076661 80912152618.

26. Kranc W, Brąert M, Budna J, Celichowski P, Bryja A, Nawrocki MJ, Ożegowska K, Jankowski M, Chermuła B, Dyszkiewicz-Konwińska M, Jeseta M, Pawelczyk L, Bręborowicz A, Rachoń D, Bruska M, Nowicki M, Zabe M, Kempisty B. Genes responsible for proliferation, differentiation, and junction adhesion are significantly up-regulated in human ovarian granulosa cells during a long-term primary in vitro culture. Histochem Cell Biol. 2018; DOI:10.1007/s00418-018-1750-1.

27. Virant-Klun I, Omejec S, Stimpfel M, Skerl P, Novakovic S, Jancar N, Vrtacnik-Bokal E. Female Age Affects the Mesenchymal Stem Cell Characteristics of Aspirated Follicular Cells in the In Vitro Fertilization Programme. Stem Cell Rev Reports. 2019;15:543-57; DOI:10.1007/ s12015-019-09889-0.

28. Bruckova L, Soukup T, Visek B, Moos J, Moosova M, Pavelkova J, Rezabek K, Kucerova L, Micuda S, Brcakova E, Mokry J. Proliferative potential and phenotypic analysis of long-term cultivated human granulosa cells initiated by addition of follicular fluid. J Assist Reprod Genet. 2011;28:939-50; DOI:10.1007/s10815-011-9617-6.

29. Schertl P, Volk J, Perduns R, Adam K, Leyhausen G, Bakopoulou A, Geurtsen W. Impaired angiogenic differentiation of dental pulp stem cells during exposure to the resinous monomer triethylene glycol dimethacrylate. Dent Mater. 2019;35:144-55; DOI:10.1016/j.dental.2018.11.006.

30. Ai A, Tang Z, Liu Y, Yu S, Li B, Huang H, Wang X, Cao Y, Zhang W. Characterization and identification of human immortalized granulosa cells derived from ovarian follicular fluid. Exp Ther Med. 2019;18:2167-77; DOI:10.3892/etm.2019.7802.

31. Liu YW, Chen B, Yang X, Fugate JA, Kalucki FA, Futakuchi-Tsuchida A, Couture L, Vogel KW, Astley CA, Baldessari A, Ogle J, Don CW, Steinberg ZL, Seslar SP, Tuck SA, Tsuchida H, Naumova A V., Dupras SK, Lyu MS, Lee J, Hailey DW, Reinecke H, Pabon L, Fryer BH, MacLellan WR, Thies RS, Murry CE. Human embryonic stem cell-derived cardiomyocytes restore function in infarcted hearts of non-human primates. Nat Biotechnol. 2018;36:597-605; DOI:10.1038/nbt.4162.

32. Huang Z, Wells D. The human oocyte and cumulus cells relationship: new insights from the cumulus cell transcriptome. MHR Basic Sci Reprod Med. 2010;16:715-25; DOI:10.1093/molehr/gaq031.

33. Sun L, Li D, Song K, Wei J, Yao S, Li Z, Su X, Ju X, Chao L, Deng X, Kong B, Li L. Exosomes derived from human umbilical cord mesenchymal stem cells protect against cisplatin-induced ovarian granulosa cell stress and apoptosis in vitro. Sci Rep. 2017;7; DOI:10.1038/ s41598-017-02786-X.

34. Matsuno Y, Kanke T, Maruyama N, Fujii W, Naito K, Sugiura K. Characterization of mRNA profiles of the exosome-like vesicles in porcine follicular fluid. PLoS One. 2019;14; DOI:10.1371/journal.pone.0217760.

35. Guo L, Zhang Y, Zhang L, Huang F, Li J, Wang S. MicroRNAs, TGF- $\beta$ signaling, and the inflammatory microenvironment in cancer. Tumor Biol. 2016;37:115-25; DOI:10.1007/s13277-015-4374-2.

36. Xu B, Zhang YW, Tong XH, Liu YS. Characterization of microRNA profile in human cumulus granulosa cells: Identification of microRNAs that regulate Notch signaling and are associated with PCOS. Mol Cell Endocrinol. 2015;404:26-36; DOI:10.1016/j.mce.2015.01.030.

37. Tu J, Cheung AHH, Chan CLK, Chan WY. The role of microRNAs in ovarian granulosa cells in health and disease. Front Endocrinol (Lausanne). 2019;10; DOI:10.3389/fendo.2019.00174.

38. Ban JJ, Lee M, Im W, Kim M. Low pH increases the yield of exosome isolation. Biochem Biophys Res Commun. 2015;461:76-9; DOI:10.1016/j. bbrc.2015.03.172.

39. Vashisht M, Rani P, Sunita, Onteru SK, Singh D. Curcumin primed exosomes reverses LPS-induced pro-inflammatory gene expression in buffalo granulosa cells. J Cell Biochem. 2018;119:1488-500; DOI:10.1002/ jcb.26309.

40. Vashisht M, Rani P, Onteru SK, Singh D. Curcumin Encapsulated in Milk Exosomes Resists Human Digestion and Possesses Enhanced Intestinal Permeability in Vitro. Appl Biochem Biotechnol. 2017;183:993-1007; DOI:10.1007/s12010-017-2478-4.

41. Horan CJ, Williams SA. Oocyte stem cells: fact or fantasy? Reproduction. 2017;154:R23-35; DOI:10.1530/REP-17-0008.

42. Wang N, Satirapod C, Ohguchi Y, Park ES, Woods DC, Tilly JL. Genetic studies in mice directly link oocytes produced during adulthood to ovarian function and natural fertility. Sci Rep. 2017;7; DOI:10.1038/ s41598-017-10033-6.

43. White YAR, Woods DC, Takai Y, Ishihara O, Seki H, Tilly JL. Oocyte formation by mitotically active germ cells purified from ovaries of reproductive-age women. Nat Med. 2012;18:413-21; DOI:10.1038/nm.2669.

44. Lee Y-M, Kim T-H, Lee J-H, Lee W-J, Jeon R-H, Jang S-J, Ock S-A, Lee S-L Park B-W, Rho G-J. Overexpression of Oct4 in porcine ovarian stem/stromal cells enhances differentiation of oocyte-like cells in vitro and ovarian follicular formation in vivo. J Ovarian Res. 2016;9:24; DOI:10.1186/ s13048-016-0233-z.

45. Bhartiya D. Pluripotent Stem Cells in Adult Tissues: Struggling To Be Acknowledged Over Two Decades. Stem Cell Rev Reports. 2017;13:71324; DOI:10.1007/s12015-017-9756-y.

46. Li H, Zhao W, Wang L, Luo Q, Yin N, Lu X, Hou Y, Cui J, Zhang H. Human placenta-derived mesenchymal stem cells inhibit apoptosis of granulosa cells induced by IRE1 $\alpha$ pathway in autoimmune POF mice. Cell Biol Int. 2019;43:899-909; DOI:10.1002/cbin.11165.

47. Wang Z, Wang Y, Yang T, Li J, Yang X. Study of the reparative effects of menstrual-derived stem cells on premature ovarian failure in mice. Stem Cell Res Ther. 2017;8:11; DOI:10.1186/s13287-016-0458-1.

48. Woods DC, Tilly JL. Autologous Germline Mitochondrial Energy Transfer (AUGMENT) in Human Assisted Reproduction. Semin Reprod Med. 2015;33:410-21; DOI:10.1055/s-0035-1567826.

49. Sriraman K, Bhartiya D, Anand S, Bhutda S. Mouse Ovarian Very Small Embryonic-Like Stem Cells Resist Chemotherapy and Retain Ability to Initiate Oocyte-Specific Differentiation. Reprod Sci. 2015;22:884-903; DOI:10.1177/1933719115576727.

50. Zou K, Yuan Z, Yang Z, Luo H, Sun K, Zhou L, Xiang J, Shi L, Yu Q Zhang Y, Hou R, Wu J. Production of offspring from a germline stem 
cell line derived from neonatal ovaries. Nat Cell Biol. 2009;11:631-6; DOI:10.1038/ncb1869.

51. Bhartiya D, Anand S, Parte S. VSELs may obviate cryobanking of gonadal tissue in cancer patients for fertility preservation. J Ovarian Res. 2015;8; DOI:10.1186/s13048-015-0199-2.

52. Joo BS, Jung IK, Park MJ, Joo JK, Kim KH, Lee KS. Differential expression of pluripotent and germ cell markers in ovarian surface epithelium according to age in female mice. Reprod Biol Endocrinol. 2014;12; DOI:10.1186/1477-7827-12-113.

53. Bukovsky A. Novel methods of treating ovarian infertility in older and POF women, testicular infertility, and other human functional diseases. Reprod Biol Endocrinol. 2015;13; DOI:10.1186/s12958-015-0001-8.

54. Shibahara H, Ishiguro A, Shirasuna K, Kuwayama T, Iwata H. Follicular factors determining the developmental competence of porcine oocyte. Reprod Med Biol. 2019;18:256-62; DOI:10.1002/rmb2.12269.

55. Abdollahifar MA, Azad N, Sajadi E, Mofarahe ZS, Zare F, Moradi A, Rezaee F, Gholamin M, Abdi S. Vitamin C restores ovarian follicular reservation in a mouse model of aging. Anat Cell Biol. 2019;52:196-203 DOI:10.5115/acb.2019.52.2.196. 